\title{
Resectable Hepatocellular Carcinoma
}

National Cancer Institute

\section{Source}

National Cancer Institute. Resectable Hepatocellular Carcinoma. NCI Thesaurus. Code

C7691.

A hepatocellular carcinoma that is amenable to surgical resection. 